\title{
O valor de cada artista
}

\author{
Ana Cavalcanti \\ Universidade Federal do Rio de Janeiro
}

\section{Resumo}

Como definir o valor de um artista? E de uma obra de arte? As respostas a essas questões que hoje são definidas por agentes do mercado, há séculos desafiam críticos, teóricos e historiadores da arte. Aqui propomos algumas ideias resultantes do confronto entre um trabalho contemporâneo do coletivo de artistas Filé de Peixe, e dois textos críticos publicados na França em 1708 e 1882. O confronto improvável entre esses discursos nos leva a pensar sobre as mudanças na avaliação crítica das obras no decorrer da história e sobre as relações entre artistas, público e mercado de arte.

Palavras-chave: crítica de arte; recepção da obra de arte; mercado de arte.

\section{Abstract}

How to value art? What determines the value of an artists work? The answers to these questions currently defined by art market agents, for centuries have defied critics, theorists and art historians. Here we propose some ideas derived from the confrontation between a contemporary artistic experience of the art collective Filé de Peixe, and two critical texts published in 1708 and 1882 in France. The improbable confrontation between these discourses makes us think about the changes in the critical evaluation of the works along the time and on the relationship between artists, the public and the art market.

Keywords: art criticism; reception of the artwork; art market .

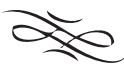

Quem se interessa por artes visuais já deve ter participado, uma vez ou outra, de alguma conversa acalorada sobre o valor das obras de arte no mercado. Esse tema espinhoso suscita discussões apaixonadas. Gostaria de contribuir com algumas reflexões sobre o assunto a partir de duas histórias, uma que presenciei há alguns dias no Rio de 
Janeiro, e outra reconstituída a partir de comentários escritos em Paris em 1882 sobre um texto de 1708. Vejamos que ideias este confronto pode nos sugerir.

No último mês de setembro, o tema do mercado de arte foi abordado no ciclo de palestras Por que ArtRio? organizado por discentes do Programa de Pós-Graduação em Artes Visuais da Escola de Belas Artes da UFRJ, ${ }^{1}$ em paralelo à quinta edição da Feira ArtRio. ${ }^{2}$ Foram convidados ao debate "artistas, teóricos e profissionais envolvidos em diversos segmentos do mercado de arte" com o objetivo de "articular posicionamentos e opiniões diversas para fomentar e qualificar o diálogo sobre a cena artística carioca contemporânea”, conforme se podia ler no material de divulgação publicado nas redes sociais.

Expondo visões contrastantes de artistas de gerações distintas, uma das mesas de palestras foi especialmente estimulante. Ali se reuniram, além da historiadora da arte Angela Ancora da Luz, os artistas Fabrício Cavalcanti, Alex Topini e Rubem Grilo.

Fabrício e Alex, de 36 e 37 anos respectivamente, fazem parte da geração de artistas cariocas que apareceram no circuito há uma década; juntamente com Fernanda Antoun integram o coletivo Filé de Peixe que vem atuando desde 2006. ${ }^{3}$ Já Rubem Grilo, nascido em 1946, iniciou sua carreira artística nos anos 1970 e tem seu lugar reconhecido na história da arte brasileira.

O que mais me tocou ao final das palestras foi o distanciamento quase intransponível que parecia existir entre o posicionamento de Rubem Grilo e o dos jovens artistas. Ao expor suas convicções, Grilo nos emocionou a mim e a muitos dos presentes. Reafirmou, em outras palavras, uma declaração feita em 1999 quando, expondo suas ideias sobre a arte, disse que "ao se expressar, certas pessoas transmitem sua experiência de vida", e essa é uma "questão de autenticidade, de ser verdadeiro consigo mesmo e se realizar de acordo com suas necessidades particulares" (GRILO, 1999, p. 113-118). Ou seja, para ele, o significado da arte diz respeito à realização profunda da personalidade do artista, em seus aspectos emocional e intelectual. Ao concluir, afirmou que se recusava a fazer parte de uma corrida de cavalos na qual o público faz suas apostas, deixando claro seu entendimento de que a arte não tem nada a ver com o jogo do mercado. Seu comentário respondia à pergunta "Por que ArtRio?" de forma categórica. Ele não estaria presente na feira de arte.

Antes de sua fala, o coletivo Filé de Peixe, representado por Alex e Fabrício, des$\infty<\infty<\infty<\infty<\infty<\infty<\infty<\infty<\infty<\infty<\infty<\infty<$

$1 \mathrm{O}$ evento foi realizado na Escola de Artes Visuais do Parque Lage em 4 de setembro de 2015, organizado pelas doutorandas Mariana Estellita e Iaci Santos, e pela mestranda Flora Pereira Flor do PPGAV-EBA, com apoio da EBA/UFRJ, do Centro de Letras e Artes da UFRJ e da Organização Social Oca Lage / Secretaria de Cultura do Estado do Rio de Janeiro.

2 A ArtRio é uma feira internacional de artes visuais realizada anualmente no Rio de Janeiro desde 2011. A quinta edição se realizou de 9 a 13 de setembro de 2015, nos armazéns do Pier Mauá, região portuária do Rio. Mais informações em http://www.artrio.art.br/pt-br/feira-internacional.

3 O Coletivo Filé de Peixe já teve entre seus integrantes diversos e numerosos artistas. Atualmente (setembro de 2015) é formado por Alex Topini, Fabrício Cavalcanti e Fernanda Antoun. 
crevera e comentara algumas de suas práticas artísticas com destaque para a coleção $\mathrm{CM}^{2}$ ARTE CONTEMPORÂNEA. Trata-se de uma coleção em andamento, iniciada em 2012, reunindo trabalhos de $1 \mathrm{~cm}^{2}$ adquiridos junto a Antonio Dias, Cildo Meirelles, Ernesto Neto, Rosângela Rennó, Nuno Ramos, Ronald Duarte, entre outros, de um total de 94 artistas até o momento. O processo de aquisição faz parte do trabalho. O coletivo visita cada artista em seu ateliê e, caso a proposta da compra seja aceita, calcula-se o preço ali mesmo e se define o valor médio do $\mathrm{cm}^{2}$ da obra com a ajuda do próprio artista. Um dos resultados da coleção é uma classificação dos artistas a partir dos valores de seus trabalhos no mercado, pois ao lado de cada centímetro, a quantia paga é informada, como se vê na Figura 1.

Não se pode negar que a coleção responde a uma curiosidade do público. "Quanto vale $1 \mathrm{~cm}^{2}$ de desenho do Cildo Meireles? E $1 \mathrm{~cm}^{2}$ de pintura do Daniel Senise, Carlos Vergara ou Antonio Dias? E $1 \mathrm{~cm}^{2}$ de fotografia da Rosângela Rennó ou $1 \mathrm{~cm}^{2}$ de gravura da Anna Bella Geiger, quanto vale?" são perguntas que introduzem a apresentação do $\mathrm{CM}^{2}$ ARTE CONTEMPORÂNEA no site http://www.coletivofiledepeixe.com/.

É importante saber que embora o Filé de Peixe venda os centímetros das obras pelo valor pago aos artistas sem acrescentar nenhum centavo a mais, os primeiros compradores vem recebendo ofertas inflacionadas por parte dos que não conseguiram seus exemplares nas ocasiões especiais em que o Filé fez a obra acontecer. ${ }^{4}$ Alex Topini e Fabrício Cavalcanti contaram que esse fato deixou os galeristas estressados, confusos e inquietos com os preços alcançados pelos centímetros quadrados e com os possíveis reflexos no mercado.

Com o $\mathrm{CM}^{2}$ o Filé de Peixe procurou intervir "criticamente sobre processos de recepção e circulação da arte enquanto mercadoria, investigando as relações entre arte e vida, as instâncias limítrofes entre objeto e produto, entre colecionismo e consumo", conforme declaram em sua página on-line.

Quando se encerraram as palestras e o público pode participar do debate, foi este o trabalho que suscitou o maior número de perguntas. "Qual a reação dos artistas ao saberem o valor de seu centímetro quadrado e compará-lo ao valor dos centímetros dos demais?", "Qual artista tem o centímetro quadrado mais caro?", "Vocês farão uma atualização dos preços declarados dos centímetros quando a cotação de um ou outro artista mudar na vida real?", e assim por diante, se sucediam as questões do público. Assistindo a esse debate animado, senti vivamente que Rubem Grilo, quieto e sem perguntas a responder, parecia um Dom Quixote num mundo transformado, um artista admirável por seus ideais e convicções de outros tempos.

Mas, até que ponto estamos vivendo tempos novos? Não é antiquíssima a relação entre arte e mercado? Ou a classificação dos artistas numa escala de valores?

Para pensar sobre isso, convido os leitores a me acompanhar numa viagem no

$\alpha<<<<<<<<<<<<<<<<<<<<<<<<>$

4 Nessas ocasiões o coletivo atende um a um os interessados na coleção. Estes devem formar uma fila e aguardar pacientemente sua vez, e só podem comprar um número limitado de centímetros. 
tempo auxiliados por um texto escrito há centro e trinta e três anos, relativo a outro texto anterior, datado de mais de três séculos. Sim, é impossível viajar ao passado, mas podemos ao menos ler as mensagens que nossos antecessores nos legaram, e tentar interpretá-las com nossa sensibilidade. Uma sensibilidade marcada por nosso próprio tempo, é verdade, mas com a qual, acredito, podemos vislumbrar concepções de mundo distantes de nós, às vezes nos surpreendendo por não serem assim tão diferentes das nossas.

O texto ao qual me refiro se intitula "A Balança dos pintores por Roger de Piles" e foi escrito em 1882 por Clément de Ris (1820-1882), museólogo, colecionador e crítico de arte francês. Seu artigo, publicado na Gazette des Beaux Arts, uma das mais influentes revistas francesas especializadas em artes no século XIX, procurava expor as falhas de um sistema de avaliação de artistas proposto por Roger de Piles (1635-1709) em 1708.

Nota-se que Clément de Ris se divertiu ao encontrar no documento do século XVIII material para reflexão sobre as mudanças no gosto entre os amantes da arte no decorrer dos cento e oitenta anos passados. De fato, De Ris explica que se interessou pelo sistema de De Piles, não porque reconhecesse um valor qualquer nesta "aberração de uma mente engenhosa", mas porque inadvertidamente tal "balança" fornecia informações sobre as tendências do gosto na França do início do século XVIII (DE RIS, 1882, p. 569).

Vejamos qual fora o procedimento de Roger de Piles (1635-1709), teórico das artes e diplomata francês, membro da Académie royale de peinture. Para chegar a um valor numérico com o qual pudesse comparar os pintores entre si, De Piles dividiu a Pintura em quatro elementos: composição, desenho, colorido e expressão. Em seguida, criou uma tabela com cinco colunas, colocando na primeira os nomes dos mais conhecidos pintores. Nas quatro colunas seguintes, como um professor que avalia seus alunos, atribuiu notas à composição, ao desenho, ao colorido e à expressão de cada pintor, como pode ser visto nas duas páginas da "balança" reproduzidas na Figura 2. Numa escala de zero a vinte, o grau vinte correspondia à perfeição, o zero ao fracasso. Embora não tenha incluído uma última coluna na qual somasse todos os graus de cada pintor, De Piles propiciou com sua tabela uma comparação numérica entre os artistas.

Criticando a proposta de seu antecessor, Clément de Ris comentou que a "Balança dos pintores é um procedimento de avaliação que, à primeira vista, parece substituir o julgamento por uma adição", porém, como cada um pode modificar os graus atribuídos por De Piles, "segue-se que tais cifras exprimem unicamente as simpatias ou repugnâncias pessoais, e haverá tantas somas diferentes quanto opiniões diversas" (DE RIS, 1882, p. 569). O que mais impressionou De Ris foram os disparates da tabela na qual Leonardo da Vinci alcançou 49 pontos, enquanto Otto Venius conseguiu 47 e Taddeo Zuccari 46. A ínfima diferença de pontos separando o talento de Leonardo dos outros dois pintores o espantava. Porém o maior absurdo, de seu ponto de vista, foi o valor atribuído a Michelangelo cuja soma atingiu parcos 37 pontos. De Ris indicou ainda que os protegidos de De Piles eram os coloristas e os artistas franceses. Correggio atingia 53 pontos, Rembrandt 50, Rubens 65 (o mais bem avaliado), Poussin 53 e Lesueur 49. "O que provam 
essas cifras? Nada; senão os gostos, as preferências do próprio de Piles. Ninguém pode imaginar que se possa encontrar aí a sombra de uma verdade e a aparência de uma justiça”, concluía Clément de Ris (1882, p. 570).

Mas a análise da "balança dos pintores" lhe permitiu observar que De Piles, "sem querer" nos dera "a medida do gosto dominante no final do século XVII e início do XVIII" já que "suas avaliações respondiam às avaliações correntes do público" (DE RIS, 1882, p. 570). O problema, segundo De Ris, é que ao seguir a tendência, Roger de Piles escolhera um caminho fadado a ser ultrapassado, pois a cada vinte anos mudam as tendências, e os que as seguem passam da vanguarda à retaguarda no correr do tempo.

Para provar seu argumento, De Ris prosseguia relatando que dez anos após a morte desse "legislador da arte" autor da "Balança dos pintores", o sucesso de Watteau era incontestável, e "as doutrinas de De Piles podiam juntar-se aos velhos trastes vendidos em bricabraques” (DE RIS, 1882, p. 570). Avançando em suas conjecturas, se perguntava que nota De Piles teria dado a Greuze, o que teria pensado de David e de sua escola? Que julgamento teria feito sobre Gros e Ingres? E quanto a Delacroix, os realistas, Courbet e Manet? Segundo Clément De Ris, De Piles enlouqueceria diante do Enterro em Ornans de Courbet. Todas as novidades da arte francesa causariam embaraço aos que desejassem utilizar a Balança dos pintores cujo valor, afinal, seria apenas o de ter se tornado um sinal dos tempos (DE RIS, 1882, p. 571).

Após ler os comentários de Clément de Ris, é interessante reler as palavras do próprio Roger De Piles explicando os motivos que o levaram a projetar seu método em 1708. Segundo ele, algumas pessoas que desejavam conhecer o mérito de cada pintor de reputação estabelecida lhe "pediram que fizesse uma espécie de balança", de modo que avaliando os aspectos das obras de cada pintor, se pudesse julgar o valor do conjunto (DE PILES, 1708, p. 489). Ou seja, De Piles estaria respondendo a uma demanda do público que desejava ter um guia para avaliar os artistas. Ora, embora não diga que esse interesse estivesse voltado ao valor das obras no mercado de arte, o fato de ter usado cifras e números facilitava esse uso por parte de possíveis compradores. Isso é tão verdadeiro que sua tabela foi usada para se pensar nos preços do mercado de arte, até mesmo recentemente por economistas interessados no assunto (GRADDY, 2013).

Por outro lado, De Piles acrescenta que fez a experiência "mais para [se] divertir do que converter os outros ao [seu] sentimento", já que "os julgamentos são diferentes demais nessa matéria, para que se possa crer possuir a razão sozinho". Pedia então que lhe dessem "a liberdade de expor o que pensa", assim como deixava aos outros "a liberdade de conservar suas ideias" que podiam ser "inteiramente diferentes" das suas (DE PILES, 1708, p. 489-490). Portanto, estava consciente de que sua balança não eliminava a subjetividade do julgamento.

O que me encanta ao ler os textos de Clément de Ris e de Roger de Piles é perceber as continuidades e transformações em ação no campo artístico. Ambos tem consciência da fluidez e subjetividade dos julgamentos em matéria de arte. Nesse ponto observamos uma sensibilidade que permanece. Tanto De Piles quanto De Ris reconhecem que o gos- 
to é variável, o que uns julgam bom, não agrada a outros.

Mas também se notam mudanças no pensamento vigente sobre a arte no século XIX (aqui representado por De Ris) em relação à concepção em curso no início século XVIII (pensamento de Roger de Piles). A história está fortemente presente na visão que Clément de Ris tem sobre as obras de arte. Seus argumentos para desqualificar a Balança dos Pintores de De Piles se nutrem da história da arte. Ele percebe as tendências que se sucedem, as etapas que chegam umas após às outras modificando o gosto dos franceses, e acusa seu antecessor de não ter percebido que a cada vinte anos o gosto se transforma.

De fato, se Roger de Piles afirma que as pessoas podem ter opiniões diversas sobre as obras de arte e expressar suas preferências, também é certo que concebe as regras da arte como permanentes, imutáveis, indiferentes à passagem do tempo. Ao dividir a Pintura em quatro aspectos - composição, desenho, colorido e expressão - a partir dos quais avalia o desempenho de cada artista, estabelece critérios rígidos quanto às características de excelência de cada um desses elementos, ignorando que soluções diferentes podem ser igualmente boas. É o que podemos deduzir ao ler sua conclusão, na qual, prevendo que receberá críticas dos que tem sentimentos diversos dos seus, De Piles acrescenta que para julgar corretamente é preciso conhecer bem todos os aspectos da Pintura:

[...] minha opinião sobre meus próprios sentimentos não é tão boa assim que não me permita prever que certamente serei severamente criticado por minhas escolhas: mas advirto que para criticar sabiamente é necessário ter um perfeito conhecimento de todas as partes que compõem a obra e das razões que fazem dela um bom conjunto. Pois muitos julgam um quadro pela única parte que amam, e não levam em conta as que não conhecem ou das quais não gostam (DE PILES, 1708, p. 389).

A convicção de De Piles, sua certeza de que existe um conhecimento objetivo sobre a pintura e uma maneira certa de julgar as obras de arte é para nós, assim como fora para Clément de Ris em 1882, um sinal da passagem do tempo. Tal concepção não seria mais possível para os que viveram a batalha entre românticos e neoclássicos nas primeiras décadas do século XIX. Roger de Piles, homem do século XVII e início do XVIII, não viu os artistas se dividirem entre as duas tendências. Muito diferente foi a experiência de Clément de Ris que participou do combate colocando-se ao lado dos românticos e mais tarde, sendo chamado para trabalhar no Museu do Louvre, conforme escreveu Charles Ephrussi (1849-1905), "sentiu, pelo efeito de ponderação que produz o espetáculo habitual das obras-primas as mais diversas, um salutar apaziguamento dos impulsos de primeira hora" e "aprendeu a respeitar, na multiplicidade tão variada de suas formas, as manifestações mais opostas da arte” (EPHRUSSI, 1882, p. 399). 
O que foi possível a Clément de Ris era inacessível a Roger de Piles: aprender a respeitar as manifestações mais opostas da arte. Do mesmo modo, a ironia contemporânea do coletivo Filé de Peixe ao intervir criticamente nos processos do mercado de arte, incorporando a concepção da obra de arte como mercadoria em seu trabalho, seria incompreensível para Clément de Ris ou Roger de Piles.

Mas então por que, se sabemos das diferenças no pensamento sobre a arte em cada época, confrontamos o CM² ARTE CONTEMPORÂNEA, que teve início em 2012, com a Balança dos pintores de 1708 ?

Nessas duas manifestações aparece a ideia de uma classificação, uma escala numérica que ordena os artistas segundo seus valores. No entanto, enquanto Roger de Piles procura definir sua tabela a partir de aspectos da obra de cada artista, o critério de classificação do $\mathrm{CM}^{2}$ é simplesmente o preço que as obras alcançam no mercado. Não há mais nenhuma relação com o que se observa nas obras, não entram em discussão seus aspectos plásticos ou seu conteúdo expressivo. Isso nos faz perguntar em que se baseia o mercado para definir o valor de um trabalho.

O CMํㄹ ARTE CONTEMPORÂNEA parece constatar um esvaziamento da arte, como se já não houvesse um sentido maior na produção dos artistas, tudo se resumindo à especulação financeira. E no entanto, o trabalho do coletivo Filé de Peixe toca o público. Há uma verdade ali na qual todos estamos imersos, uma verdade que nos incomoda e interessa.

Não dá para negar a presença do mercado na produção artística. Sem compradores, como poderiam os artistas continuar sua atividade? De fato, a relação com o mercado existe há muito tempo, ao menos desde o século XV. E aqui me permitam mencionar outro caso que nos ajuda a aprofundar nossos pensamentos sobre essa relação.

Giorgio Vasari (1511-1574) conta uma história sobre Michelangelo (1475-1564), em sua "Vidas dos artistas" (1550/1568). Diz Vasari que Michelangelo, quando jovem, esculpiu em mármore um cupido adormecido para Lorenzo, filho de Pierfrancesco de' Medici, provavelmente a partir de um modelo antigo da coleção do próprio Lorenzo.

Pelo que relata Vasari, quando Michelangelo mostrou o cupido para Pierfrancesco, este lhe teria dito que se enterrasse a estátua dando-lhe um aspecto envelhecido, ela passaria por uma peça antiga. E que Michelangelo poderia levá-la à Roma, vendendo-a por um preço muito mais elevado por lá. E Vasari continua: "Diz-se que Michelangelo então a preparou para que parecesse antiga, o que não é de admirar, pois tinha engenho para isso e mais" (VASARI, 2007, p. 355). Em Roma, o cupido teria sido vendido para o Cardeal de San Giorgio. Este porém, quando soube da fraude, devolveu-o.

Ora, se essa história é verdadeira, quando Pierfrancesco aconselhou Michelangelo a vender seu cupido fazendo-o parecer obra da antiguidade clássica, isso era reflexo da valorização dos trabalhos antigos em relação aos dos artistas do século XV. O curioso é que Vasari critica o cardeal por não ter tido a sensibilidade de perceber que essa era uma obra talvez ainda melhor que a dos antigos. Portanto, o comprador fora tolo em devolver a escultura, pois não percebeu que o artista de seu tempo tinha tanto ou mais valor que 
os antigos. Deveria ter guardado consigo a obra de Michelangelo. Para Vasari, o cardeal S. Giorgio, fora "incapaz de reconhecer a virtude da obra, que consiste na perfeição, pois que equivalem as modernas às antigas, quando excelentes. Maior vaidade é a dos que preferem nomes a fatos." (VASARI, 2007, p. 355) ${ }^{5}$ Se o cardeal soubesse o quanto as obras de Michelangelo seriam valorizadas!...

Esse relato reforça a noção de que o valor da arte não se resume aos preços das obras no mercado, pois as avaliações são flutuantes. O que foi valorizado no mercado em certa época, deixou de ser. O que hoje é valorizado, poderá perder seu valor no futuro. Portanto, há algo mais que está em jogo na relação dos artistas com o público. Algo que chama a atenção das pessoas e as atrai para determinadas obras. Assim, por mais que se tenha uma visão crítica sobre o mercado de arte, ele de fato não age sozinho, mas responde ao encantamento do público. Este encantamento é a parte inexplicável, aquilo que não se sabe bem por que nos emociona, e acontece quando o artista faz vibrar em nós uma corda até então desconhecida.

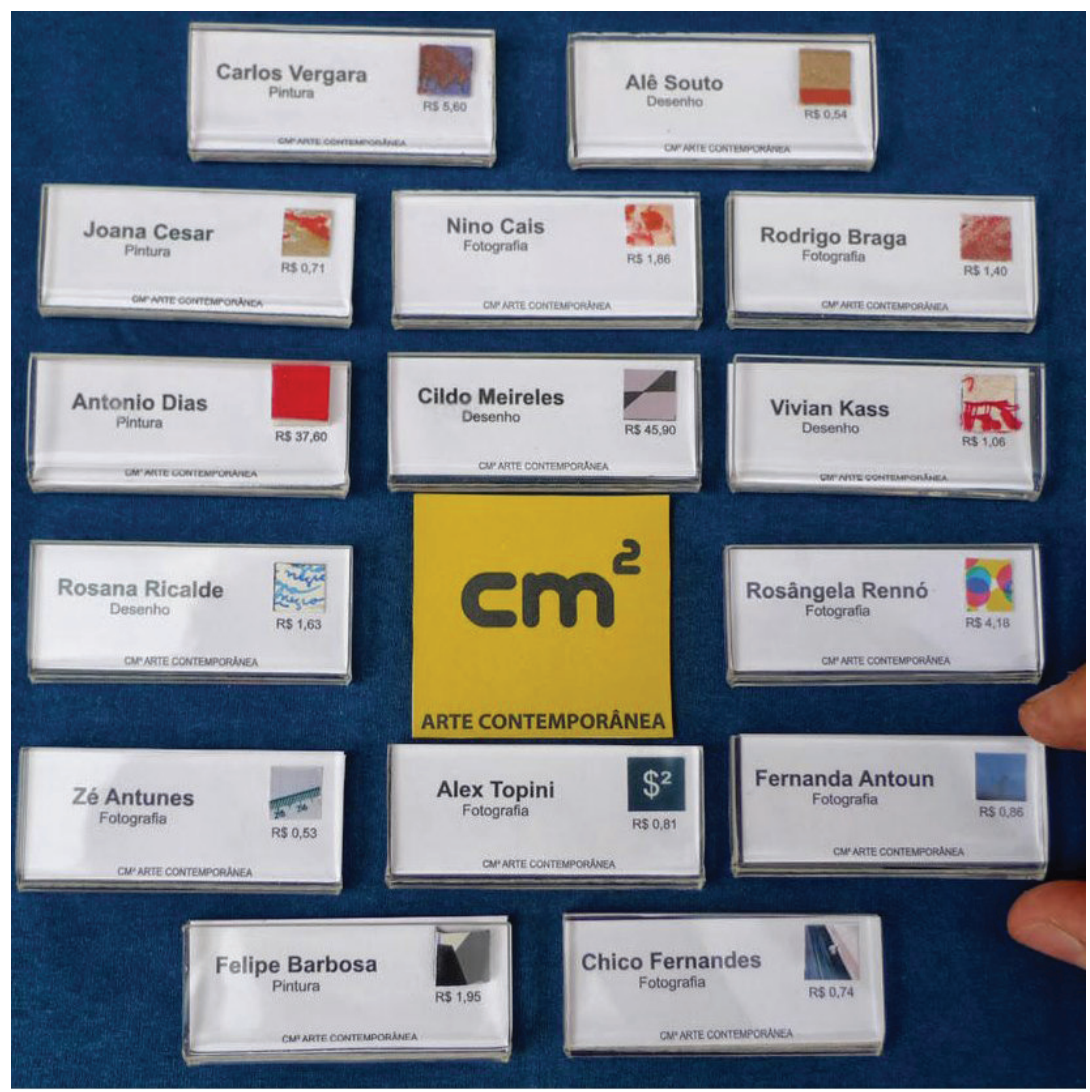

Figura 1

Coletivo Filé de Peixe. CM2 ARTE CONTEMPORÂNEA

$\alpha<<<<<<<<<<<<<<<<<<<<<<<<<<>$

5 Tradução de Luiz Marques disponível em http://www.mare.art.br/detalhe.asp?idobra=596 


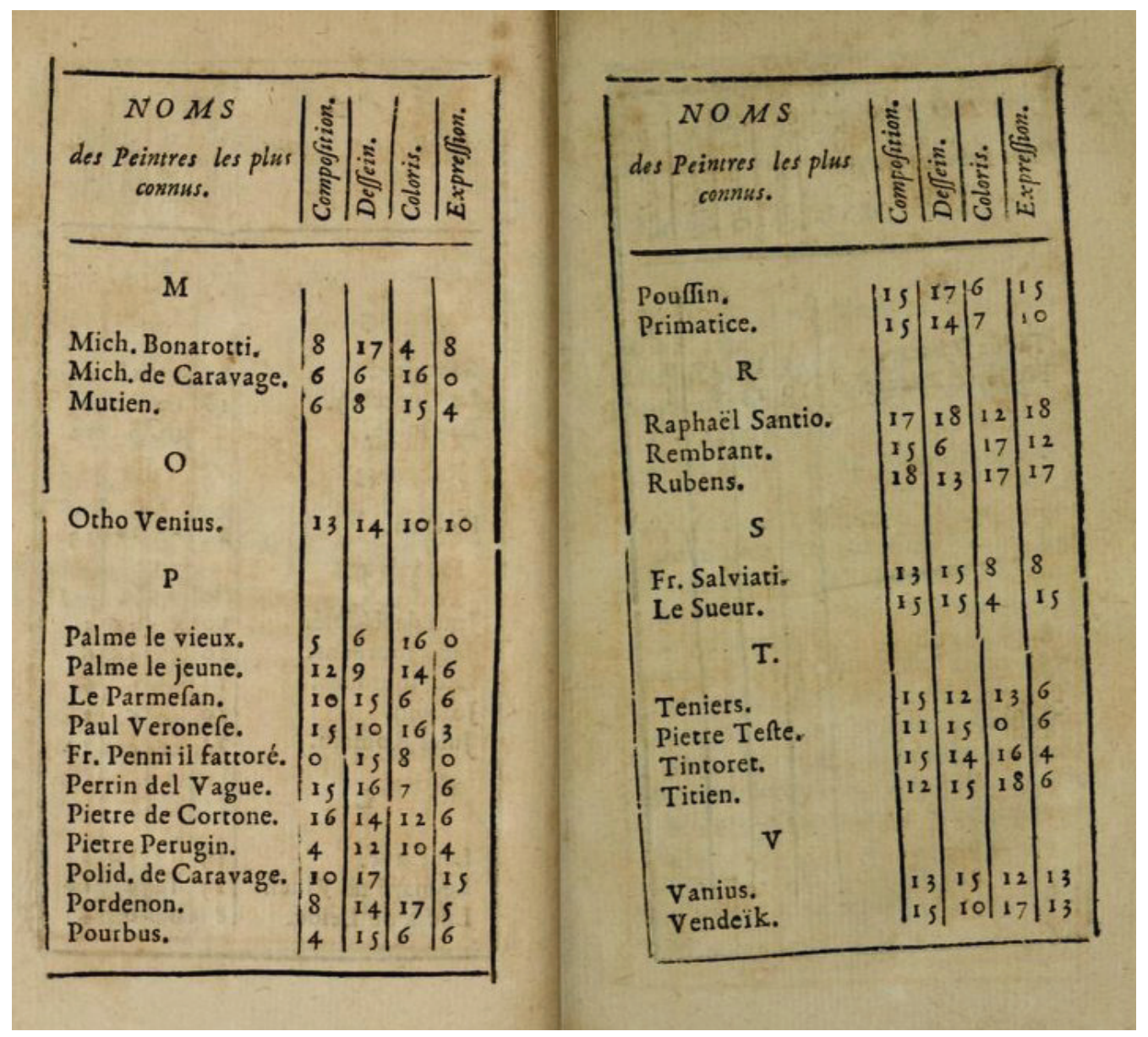

Figura 2

Duas páginas da Balança dos Pintores, de Roger de Piles, 1708

\section{Referências bibliográficas}

COLETIVO FILÉ DE PEIXE. <http://www.coletivofiledepeixe.com/> Acesso em: 6 set. 2015 .

DE PILES, Roger. Cours de peinture par principes. Paris: Jacques Estienne, 1708. Disponível em <https://archive.org/details/depeintureparpri00pile $>$. Acesso em: 20 set. 2015.

DE RIS, Clément. La Balance des Peintre de Roger de Piles. Gazette des Beaux Arts, Paris, p. 569-571, 1 jun. 1882. 
EPHRUSSI, Charles. Clément de Ris. Gazette des Beaux Arts, Paris, p. 398-402, 1 nov. 1882.

GRADDY, Kathryn. Taste Endures! The Rankings of Roger de Piles (†1709) and Three Centuries of Art Prices. Journal of Economic History, Cambridge, v. 73, n. 3, p. 766-791, set. 2013.

GRILO, Rubem. Gravura, linguagem e vida. In: OFICINAS: gravura. Rio de Janeiro: SENAC, 1999. p. 113-118. Disponível em <https://www.escritoriodearte.com/artista/ rubem-grilo/> Acesso em: 10 set. 2015.

LABRA, Daniela. Alex Topini: Feiras. Rio de Janeiro, 2 de julho de 2012. Disponível em <http://www.artesquema.com/escritos/alex-topini-feiras/> Acesso em: 10 set. 2015.

MARQUES, Luiz. MARE. Museu de Arte para a pesquisa e educação. Disponível em <http://www.mare.art.br/> Acesso em 3 set. 2015.

VASARI, Giorgio. Vie des artistes. Paris: Bernard Grasset, 2007. 